\title{
Building a modern economic system: basic framework, key issues, and theoretical innovation
}

Building a modern economic system

\author{
Zhibiao Liu \\ School of Economics, Nanjing University, \\ Nanjing, China
}

\begin{abstract}
Purpose - The construction of a modern economic system is a symbolic and strategic choice for large developing economies on the path toward high-quality economic development. The paper aims to discuss this issue.

Design/methodology/approach - The overall framework aims to adhere to "One Policy and One Mainline" to build an innovation-driven, synergistic industrial system and a "with three-qualities" economic system (with efficient market mechanisms, energetic micro-agents and appropriate macroeconomic regulation).

Findings - The strengthening of the real economy and construction of a modern industrial system constitute the material basis for supporting this system and framework. As major decision making and theoretical innovation in empirical practice, building a modern economic system can also contribute substantially toward developing the applied economic theory of socialism with Chinese characteristics.

Originality/value - Building a modern economic system in China necessitates, without exception, the construction of various subsystems encompassing industrial, market, distribution, regional development, green development, open and economic institutional aspects.
\end{abstract}

Keywords Modern economic system, High-quality development, Real economy,

Economic theory innovation

Paper type Research paper

A general guiding principle of China's economic construction in the new era is to shift from the pursuit of a high-speed economy to the pursuit of high-quality economic development to accelerate the establishment of a modernized economic system (Liu, 2018a). This principle is the strategic goal of China's development and an urgent requirement in the crucial period of transforming the development model, optimizing the economic structure and switching the growth momentum. General Secretary Xi Jinping pointed out that building a modern economic system resembles writing a substantial article with not only a major theoretical proposition but also a major practical perspective to be discussed in depth through the integration of theory and practice. An in-depth discussion of this important paper is undoubtedly valuable and effective in grasping the objectives, connotations and key points of building a modern economic system; seeking solid and practical policy measures and actions; or summing up lessons and possible theoretical innovations. This process enriches the valuable collection of the socialist economic theory with Chinese characteristics.

(C) Economic Research Journal. Published in China Political Economy. Published by Emerald Publishing Limited. This article is published under the Creative Commons Attribution (CC BY 4.0) licence. Anyone may reproduce, distribute, translate and create derivative works of this article (for both commercial and non-commercial purposes), subject to full attribution to the original publication and authors. The full terms of this licence may be seen at http://creativecommons.org/licences/by/4.0/legalcode. Originally published in Simplified Chinese in Economic Research Journal.

This paper is funded by the Special Project of the Ministry of Education to Study and Illuminate the Policies of the 19th CPC Congress.

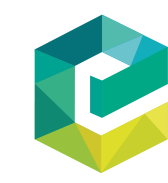

China Political Economy Vol. 2 No. 1, 2019 pp. $73-84$ Emerald Publishing Limited 2516-1652 DOI 10.1108/CPE-04-2019-0010 
CPE

2,1

\section{Strategic significance of a large developing power's effort to build a modern economic system}

The modern economic system refers to an economic concept of high originality that is innovatively proposed by the General Report the 19th National Congress of the Communist Party of China (CPC) based on the idea that "for a country to be strong, the economic system must be strong," and the wisdom of the entire Party and the country's citizens. Building a modern economic system, which is the economic foundation of a modernized power, is an important approach to address the major contradictions in the new era by sufficiently emphasizing its role and strategic position.

The major contradictions in Chinese society have undergone profound changes at the new era of rapid development of productivity. These changes are manifested in two ways. First, the people's needs have evolved into the demand for a better life beyond material factors to include improved education, secure jobs and decent incomes, reliable social security, high levels of healthcare, comfortable living conditions, a beautiful environment, and a rich spiritual and cultural life. Second, the problem of addressing backward productivity has evolved into the problem of addressing the imbalance and inadequacy of development and the deficient total supply problem has changed into a structural problem. However, the major social contradictions in the new era also have two characteristics that remain unchanged. The first constant characteristic is that China is still and will remain at the primary stage of socialism on a long-term basis, given the fundamental reality that the country is still the largest developing economy in the world. Therefore, taking full account of this picture, the strategic policy to achieve the Two Centenary Goals aims to focus on economic construction and unswervingly prioritize development in governing and rejuvenating the country. The second constant characteristic is related to the economic attributes of the major contradictions in society. In the past, China's socioeconomic development aimed primarily to overcome the shortage economy, and now, albeit the rapidly developing productivity, the development quality still lags far behind that of developed countries, as reflected in the unbalanced and inadequate structure on the supply side and the upgrading demand structure on the demand side. The major social contradiction in the new era is essentially a contradiction in the levels of development of productive forces. To date, we have adhered to development as the top priority and economic construction as the focus, with a view to addressing the issues of fairness or foulness, structural imbalance and quality rather than solving the problem of the absence or affluence of supply.

At the stage of speed-oriented development, the one dimension challenge is solving the problem of absence or affluence of suppIy, while at the stage of quality-oriented development, the multidimensional tasks will produce more complex problems, which entails the fundamental upgrade of the idea of economic centered development, with a speed-oriented system being transformed into a quality economic system. We should construct an economic system with the methodology of systematic thinking to tackle the aspects as follows.

First, they differ in terms of their historical conditions and backgrounds. In the pursuit of high-speed development, we are faced with the problem of living standards in poverty or subsistence level, with the shortage economy as its basic feature. The background of the Cold War between East and West also requires China to implement catch-up strategies in an unbalanced manner across departments and regions. In the pursuit of high-quality development, China is in a comprehensive well-off phase that accelerates into the basic modernization stage. The economy is generally overheating, and the unbalanced catch-up strategy should be gradually replaced by a balanced development approach.

Second, they differ in terms of dimensions of development evaluation. The high-speed development stage fits in with a single-dimensional evaluation in which quantity is the main policy pursuit. In the high-quality development stage, a multidimensional evaluation is required, which is not limited to quantity but emphasizes quality as the most fundamental requirement such as the need for a better life in terms of income, education, work, social 
security, healthcare, living conditions and environment. Therefore, high-quality development embodies the new development concept in which innovation becomes the first driving force, harmony the endogenous characteristic, greenness the universal appeal, openness the necessary path and sharing the fundamental purpose.

Third, means and tools for implementation for the two are different. In the high-speed development stage, the targets of demand are homogeneous, small in quantity, narrow in scope, and clear-cut. At this point, the efficient management method would be the government speaking for the people's choice, concentrating resources to achieve unbalanced development, and using planned instruments. In the high-quality development stage, the components of the target demands are complex, large in scale, highly variable and have a prohibitive cost of information acquisition. At this stage, endogenous regulation of the market would be the optimal adjustment method. The range and scale of markets and non-markets that correspond to the needs of a better life are expanding. The market failures in the rapidly growing non-market regulation sector call for the government to change its jurisdiction and management functions.

While the small economy can achieve a specialized division of labor and cooperation by embedding into the global economy, thereby establishing an open and modern economic system that relies on external relations, for a large economy such as China, through participating in the international division of labor is also an inevitable step toward establishing a modern power. However, the most important task for China's development strategy is to build an independent and open modern economic system based on the incessantly growing and large-scale domestic demand. This truth is self-evident. Due to the limitation of the scale of domestic demand, small economies do not have the need or capability to build a large number of full-fledged modern industries with economies of scale. To survive, small economies have to abandon multiple industrial fields to leverage external markets on a wide scale and establish dependent relationships with larger and stronger economies in the world. A powerful economy with a large population, such as China, which is concerned with cost savings and economic security, has to acquire and utilize global resources, technology and knowledge by opening up. However, due to the exclusive nature of global economic competition, the core key technologies and knowledge needed for China's industrial development are impossible to exchange in the market or buy with money. These technologies and knowledge must be researched and developed independently. Otherwise, establishing a solid manufacturing industry and a strong military industry is impossible. The long-term stability of the country requires that Chinese people's jobs remain in their own hands, and that China's important and key industrial technologies must also be in the hands of the Chinese.

\section{Major connotations of construction of modern economic system}

General Secretary Xi emphasized that the modern economic system is an organic whole consisting of intra- and interrelationships among all links, levels and sectors of socioeconomic activities. In other words, this organic system consists of workers, peasants, merchants, students, and soldiers, as well as prices, financing, commodities and logistics. All aspects, directions and dimensions are connected by production, circulation, distribution, consumption, investment and reproduction links. This system cannot be understood in an isolated and one-sided manner and must be systematically analyzed in close conjunction with all aspects of the national economy.

In the past four decades, China has adhered to the construction of a socialist market economic system under the general trend of the transition economy. This reform and construction task has resulted in world-renowned achievements. China now appears to be among the world's middle-class developed countries in the next 20 years or so. Although the reform of the institutional mechanism is the basic guarantee, accelerating the development of productive forces through innovation is a fundamental need that calls for a larger and 
CPE 2,1

grander vision and program. Drawing on the development experience and some useful practices of the developed countries in the world, and according to China's national conditions, this vision and program is to build a modern economic system. According to the economic thinking of General Secretary Xi, the modern economic system primarily includes the following subsystems.

\subsection{Industrial system}

This is the foundation and core of a modern economic system. From the perspective of the modern economic growth theory, establishing an industrial system with real economic development as the goal is necessary with scientific and technological (S\&T) innovation, modern finance and human resources as input factors. The modern industrial system requires cooperation among these four elements instead of each one competing for its own sake. The overall goal is to continue to grow the real economy. The contribution of S\&T innovation in the development of the real economy will continue to increase, the ability of the financial system to serve the real economy will continue to be enhanced, and the role of human resources to support the development of the real economy will be continuously optimized.

\subsection{Market system}

This is the decisive mechanism for allocating resources in the modern economic system. Only by establishing and perfecting a market system with smooth access, well-aligned openness, full competition and normative order can an economy provide enterprises with an excellent environment of independent management and fair competition, create a space for consumers to freely choose and consume independently, realize the free flow and equal exchange of goods and factors, and lay a micro-foundation for high-quality economic development.

\subsection{Distribution system}

This is an incentive mechanism for a modern economic system. On the basis of pursuing efficiency, the basic requirements and fundamental indicators of economic modernization consist of distribution and redistribution tools to achieve reasonable income distribution among members of society, gradually narrowing the gap between income and wealth distribution, and promoting prosperity for all and inclusiveness of basic public services.

\subsection{Regional development system}

This is the spatial layout of the modern economic system. The general requirement is to balance efficiency and equity, and achieve the productivity-layout goal of high utilization efficiency of land and resources, large factor intensity, moderate ecological capacity, continuous urban agglomerations and small regional development gaps.

\subsection{Green development system}

This is the ecological and environmental basis of the modern economic system and an important part of national wealth. The general requirements are to save resources, be environmentally friendly, achieve green recycling and low-carbon development, and live in harmony with nature.

\subsection{Open system}

This is the link between the national economic system and the outside world. A high-level open economy is an economy that deeply joins the global division of labor system and has a virtuous cyclical relationship with the world economy. Such an economy not only exports 
goods and elements but also absorbs them; it does not only bring products in but also delivers them globally; and it is not only open to the East but is also open to the West and South along the "belt and road."

\subsection{Economic system}

Building a modern economic system

This is the institutional basis of a modern economic system. It is not only the Western market economic system that represents the modern market economy. The new era of socialist market economy with Chinese characteristics is characterized by giving full play to the decisive role of the market and that of the government to achieve efficient market mechanisms, energetic micro-agents and appropriate macroeconomic regulation.

China is not only the second largest economy in the world, but is also a big country in transition. First, China is still in the process of fully transitioning to the socialist market economic system. The economic systems that support the modern economic system, especially the market system, are not perfect and sound (Ning, 2017). Second, China is a developing country faced not only by underdeveloped productivity, but moreover, the problem of a highly uneven internal structure. From the relatively primitive agricultural and handicraft industries to the world's leading aerospace industry technology, China's industrial technology system has a typical gradient distribution. Therefore, the construction of a modern economic system needs to face the basic national conditions and transform many of the basic strategies that have worked effectively in the past but are no longer adapted to current national conditions.

The first fundamental strategic transformation is to shift the non-equilibrium strategy to a balanced one. The unilateral pursuit of economic speed must evolve toward protecting the ecological environment, developing key technologies, consolidating basic public services and infrastructure, and strengthening factor markets. The second fundamental strategic transformation is to move from increasing the scale of savings and the rate of capital formation to building an innovation-oriented and four-in-one synergistic industrial system. The third fundamental strategic transformation is to strengthen the market-oriented allocation of factors on the basis of market-oriented allocation of commodities. Promoting or accelerating structural transformation in the high-quality development stage is the micro-foundation for building a modern economic system. The promotion of high-speed transformation of structures depends principally on the degree of market-oriented allocation of factors, especially the role of capital markets. The fourth fundamental strategic transformation is to shift the principle of distribution from one that "gives priority to efficiency with due consideration to fairness," which has been implemented for a long time, to shared distribution based on efficiency. The objective is not only to stimulate consumption and expand domestic demand but also to alleviate social conflicts and prevent development from falling into the middle-income trap. The fifth fundamental strategic transformation, in terms of spatial relations, is to find an equilibrium point in giving priority to industrial or regional policy. The major tasks in this regard are revitalizing the countryside primarily by developing urban agglomerations, building a world-class advanced manufacturing cluster, balancing regional relations and accelerating the integration of economic development in China's major administrative regions. The sixth fundamental strategic transformation is to internalize "greenization," which meant cost-free and poverty in the past but now means income, welfare and wealth as a cleaner, low-carbon economy. The accounting of green GDP has to be strengthened, the focus should shift from the gross national product to the national ecological output value, and a compensation mechanism for the ecological environment should be built. The seventh fundamental strategic transformation is to shift from export-oriented globalization to one based on domestic demand. This change is a necessary condition for the formation of an innovation-driven economy and also the basic requirement for building an independent and modernized economic system. The eighth fundamental 
CPE 2,1

3. General framework for China's construction of a modern economic system

Building a modern economic system is the top-level design of the central government for China's economic development framework. In accordance with the policies set forth in the report of the 19th CPC National Congress, the overall framework of the modern economic system is to adhere to "One Policy and One Mainline," to build an innovation-driven, "Four-in-one" synergistic industrial system and a "with three-qualities" economic system (Yang, 2017).

Adhering to One Policy means that quality comes first, while efficiency remains a priority. This situation reflects the profound reflection of the CPC on the past development model since the 19th National Congress. China's catch-up strategy has led to world-renowned economic achievements. However, due to the tilting effect of the unbalanced development model, it has left "significant structural imbalances" that plague future high-quality development. The people's ever-growing need for a better life vs the unbalanced and inadequate development has become the major contradiction in society. To this end, we must first rectify the deviation in strategy to shift from the pursuit of a high growth rate to the pursuit of building a highquality economic system, to achieve the double catch-up in terms of the development speed and the people's livelihood and welfare. This strategic shift, superimposed by China's snowballing aging population, denotes that the development conditions have undergone tremendous changes. One of the most important phenomena is the continuous rise in factor prices. The reason is self-evident: the development speed has been reduced, but the requirements for the people's welfare and environmental protection have escalated, and so does the labor burden factor. In other words, the social cost of development has increased. If this rising cost trend cannot be offset by high-quality development forces, such as S\&T innovation and advancement of productivity growth, and cannot shift from the low-cost advantage of the past to the high added-value competitive advantage, then the internal driving force of China's future development will be attenuated. The slowdown in growth rate, coupled with the pressure of cost-driven inflation, will likely lead to a stagflation pattern in China's economic operations and entrapment in middle-income development. Therefore, promoting the three major transformations in quality, efficiency and driving force has become an inevitable choice for adhering to the principle of "quality first while giving priority to efficiency."

"One Mainline" aims to deepen the structural reform of the supply side by promoting major transformations in quality, efficiency and driving force. Addressing the "significant structural imbalance" at the present stage necessitates adjusting the structure to gear up speed, uplift quality, and elevate benefits. This is the only proper course to take to solve the major contradictions in the new era. The major problem in the current economic operation is the existence of such a "significant structural imbalance" between the supply structure, quality system and escalating social demand structure, thereby resulting in overcapacity, resource allocation distortion, inefficiency and dysfunction. To promote the construction of a modern economic system with supply-side structural reform as the main line, the focus shall be placed on accelerating the development of advanced manufacturing, strategic new industries and high-tech industries, and promoting the deep integration of the internet, Big Data and artificial intelligence into the real economy (Liu, 2018). The first step is to cut taxes and charges to reduce the burden on enterprises in the real economy. The second is to relax the administrative control and micro-control on these enterprises to enable them to participate unfettered in the new round of global competition, and let the market mechanism 
fully play its roles in self-regulation and self-repair. In other words, governments at all levels need to increase their input in promoting the integration of production factors into the real economy. Institutional innovation shall be geared toward the real economy, and economic policy and work forces shall prioritize the real economy to create a social environment that is characterized by down-to-earth and diligent entrepreneurship development.

The construction of an innovation-oriented and "Four-in-one" synergistic industrial system aims to build an industrial system with coordinated development of the real economy, S\&T innovation, modern finance and human resources. The development of the real economy is the guideline and goal. Any unhealthy tendency to break away from the development track of the real economy, which renders self-service, self-circulation and self-reinforcement for the virtual economy, will shake the foundation of the national economy and should be rectified. S\&T innovation is the first driving force for the development of the real economy. Modern finance is the blood circulation system that maintains the healthy operation of the real economy. Human resources constitute the primary productive force for building a modern economic system. Section 4 of this paper shall discuss the approaches to build this modern industrial system.

Building a "with three-qualities" economic system necessitates an efficient market mechanism, dynamic micro-agents, and appropriate macroeconomic regulation. Every major progress in the construction of China's modern economic system comes from bold reforms and innovations in systems and mechanisms that are unsuitable for the development of productive forces. The Chinese economic miracle is a major victory in market-oriented reform. Constantly adjusting and reforming the relationship between the government and the market in the future is the principal path for building a modern economic system based on the following basic principles. First, the government shall play fair instead of playing more. The administrative intervention shall be appropriately reduced through negative lists and lists of authorities and responsibilities. The "better off" standard shall tolerate no nonfeasance, ultra vires, and malfeasance in administration. Second, the Laissez-faire system shall be considered as the biggest "hand," and the government should perform more "subtraction" in matters beyond the power list. Third, Laissez-faire is not "hands off." Norms for supervision and arbitration of market activities should be formulated to correct market failures and enable the market entities in non-profit areas to provide sufficient external conditions for market development.

\section{Innovation-oriented and synergetic development of the industrial system constitutes the foundation of the modern economy}

The synergetic development of the industrial system consisting of the real economy, S\&T innovation, modern finance and human resources (hereafter referred to as "innovation-oriented and synergetic development") is a new goal of the industrial system construction that the CPC creatively devises from the perspective of factor input. This goal is also a major theoretical innovation in China's development practice that respects the laws of economic development. This concept emphasizes that growth should enable the synergies of advanced production factors and focus on improving total factor productivity. Furthermore, the production factors invested in the national economy must ultimately be infused into the real economy to encourage the financial sector to serve the real economy and leverage the modern financial mechanism to support S\&T innovation and economic growth.

In practice, building an industrial system of innovation-oriented synergetic development entails focusing on three pairs of relationships (Liu, 2018b).

\subsection{Relationship between the real economy and S\&T innovation}

The general principle is to boost incessantly the contribution of S\&T innovation in the development of the real economy. At present, the gap between China's S\&T research level and 
CPE

2,1

80

that of the world is smaller than that between the real industry level and that of the world. The major reason for this contradiction may be that China's scientific research is out of touch with the real economy. Another possible reason is that the system is not perfect enough to encourage scientists to transform their research results due to concerns about weak protection of intellectual property rights and lack of support for the industrialization of scientific research results. The gap between S\&T achievements and the real economy is an old problem. One way to solve it is to industrialize scientific research activities and serve the real economy in accordance with the laws of the market. However, not all links of scientific research activities can be industrialized. The links can be divided into two stages: the first stage is to turn money into knowledge, which is the domain of scientists, and the second stage is to turn knowledge into money, which is the entrepreneurs' business. The two cannot be confused. In the first stage, we should emphasize the originality and uniqueness of scientific research. However, in the second stage, if the scientific research activities cannot be conducted with a focus on industrialization, then the economic self-circulation process will be blocked, and a serious imbalance will emerge between the real economy and S\&T innovation.

\subsection{Relationship between the real economy and modern finance}

The general principle is to incessantly enhance the ability of modern finance to serve the real economy. The major problem in current practice is the "hollowing out" of manufacturing, that is, a situation in which excessive financial development affects the healthy development of the manufacturing sector. When the real economy is not real enough and the virtual economy is extremely virtual, the funds operate within the financial system instead of going into the real economy. At the same time, the real economy itself has overcapacity, excessive leverage, low productivity and cannot create a satisfactory rate of return for investors. Therefore, it cannot absorb sufficient development resources. In 2017, the central government was resolute in deleveraging and cutting overcapacity, which enabled many enterprises to get rid of heavy debt burdens, thereby helping the economy to gradually recover its vitality. The phenomenon of "underweighted real economy and overweighted virtual economy" is directly related to the issue of "asset shortage" in China's economic operation, which is manifested in the huge financial needs of the residents vs the limited supply of assets. Thus, the asset price is constantly raised, thereby making the development environment unfavorable to the real economy. The people's demand for a better life includes both material and cultural components along with the need to manage wealth. The added value of wealth constitutes a basic demand after the improvement of living standards. The failure to meet the growing financial management needs of residents constitutes one of the important reasons for the excessive currency inflows and accumulation of bubbles in China's real estate sector. Therefore, an important task to balance the relationship between the real economy and modern finance is to actively develop the latter so that it can provide the society with more quality assets for financial management.

\subsection{Relationship between the real economy and human resources}

The general principle is to continuously optimize the role of human resources to support the development of the real economy. We have to revitalize the real economy so that it can attract outstanding talents. The sectors where talents are willing to go are entirely based on personal choices, but from a strategic national perspective, a sector shunned by young people will not have a bright future. The mismatch between human resources and the real economy is one of the main problems encountered in China's revitalization and expansion of the real economy. To solve this problem, we must fundamentally improve the profitability of the real economy and create good material conditions to attract young people who are looking for jobs. The remuneration for technical workers, who are the pillars and future of China's manufacturing industry, must be substantially improved while implementing the chief mechanic system and encouraging workers to hold shares and contribute toward the 
fortunes of the company. The social and economic status of vocational and technical education should be escalated to enable craftsmen to live a life of dignity and decency. This development can motivate young people to become craftsmen, thereby helping to revitalize the national real economy.

Building a modern economic system

\section{Building a modern economic system necessitates solid and effective measures}

The top-level design and basic strategy for the construction of a modern economic system in the new era should be linked with grassroots innovation and needs specific actions and solid and effective policy measures. To this end, we must focus on the following aspects.

\subsection{Innovation-driven development policies centered on scientific research industrialization and marketization}

General Secretary Xi pointed out the need to "create more leading developments driven by innovation and first-mover advantage." The shift from the latecomer advantage to the first-mover advantage requires us to master a greater range of new technology sources, and go through the more time-consuming, costly, risky and difficult basic research and industrialization process. We must aim to reach the forefront of global S\&T, strengthen basic education and basic research, and achieve major breakthroughs in forward-looking and leading original results.

\subsection{Rural revitalization policy taking urban agglomerations as the center to drive the modernization of agriculture, rural areas and farmers}

Rural revitalization features not a return to the traditional "agriculture, rural areas, and farmers" pattern, but a shift to modernization in which farms become richer and more farmers become urban dwellers; the comparative earnings rate of agriculture reaches the social average and above-average levels; and the rural areas, led by industrialization, begin to enjoy an urbanized lifestyle, which does not mean turning the countryside into a city but giving it a similar lifestyle through developed infrastructure, education, healthcare, social interactions and cultural activities. Revitalizing the countryside must start with industry, talents, culture, ecology and organization, among other elements. However, relying on the development of continuous urban agglomerations to revitalize the countryside is the most important idea in China's future development of the "agriculture, rural areas, and farmers." If the Yangtze River Delta and Pearl River Delta regions have the most successful experiences and typical examples of rural revitalization in China, they can also be the development model that can be chosen for China's future development of the "agriculture, rural areas, and farmers." Without urbanization and the development of urban agglomerations, revitalizing the villages alone would be ineffective. Thus, lifting unreasonable restrictions on farmers, encouraging free flow of the population, and improving the social security system by the government are, among others, the most important steps.

\subsection{Regional coordinated development policies centered on time-space compression, increased density and reduced segmentation}

Differentiated economic policies should be formulated according to the actual situation of each region. For instance, the revitalization of old industrial bases, such as those in northeast China, necessitates rebuilding the incentive mechanism and development momentum through deepening reforms. The developed regions in the east should be required to take the lead in optimized regional development and in launching the second-step strategy of entering basic modernization. In the future, according to the reorganization principle of economic geography (time-space compression, increasing density and segmentation), building urban agglomerations will become the mainstay with a pattern of coordinated development of large, medium, and small cities as well as small towns, to accelerate the process of "citizenization." 
CPE 2,1

\subsection{Three-dimensional all-round open policy centered on building a "community of common destiny"}

At present, a new wave of globalization based on domestic demand is on the rise. China will use its own domestic demand advantage to absorb advanced global production factors to serve the country's development of an innovative economy. The policy mainly includes the following: first, focusing on the "One Belt, One Road"; establishing and improving the global value chain based on China; promoting international capacity cooperation; forming a global network of trade, investment, financing, production and service; and fostering international economic cooperation and new competitive advantages. Second is implementing a high-level trade and investment liberalization and facilitation policy, and fully implementing the pre-established national treatment plus negative list management system. And the third is giving the free trade pilot zones greater reform autonomy and exploring the construction of free trade ports.

\subsection{Supply-side structural reform policy centered on reducing corporate burdens and relaxing economic regulation}

Under the premise of maintaining a relatively stable macroeconomic environment, to reverse the "significant structural imbalance" of China's economic operation, we must find the source, path, and motivation for problem-solving through reform, which is to promote government reform through supply-side structural reforms that will inevitably actualize the decisive role of the market in resource allocation. The resulting government reform will have the dual effect of deregulation and reducing the burdens on enterprises (Liu, 2017). This move is determined by the government's reform to cut the size of the government, omit unnecessary functions and affairs, and reduce government expenditures. This dual effect also represents two key issues in the supply-side structural reform, which will inevitably stimulate the expansion of domestic demand and enhance the investment capacity of enterprises and the spending power of the people. This development will play a decisive role in cutting overcapacity, stabilizing investment expectations, increasing people's sense of acquisition, and reducing capital outflows. It will also help China transform its export-oriented global economic development model into one based on domestic demand, thereby promoting an economic cycle of independent innovation, which is expected to result in tremendous kinetic energy for development.

\section{Theoretical innovation in constructing a modern economic system}

The top-level design and major deployment of the 19th CPC National Congress on building a modern economic system not only proposed many major tasks that require practice and solid work, but also involved major innovations in the economic theory and enriched the valuable collection of socialist economic theory with Chinese characteristics.

The expression of the major contradictions in the new era, as stated in the 19th CPC National Congress Report, is an achievement with major judgment and theoretical innovation in the cognitive category and a great contribution to the development of socialist political economy. In a similar way, the general guiding principle of economic construction, that is, the construction of a modern economic system, which is proposed to solve this major contradiction, is a crucial act of theoretical innovation and a key contribution to the development of the applied economic theory of socialism with Chinese characteristics. The essence of the modern economic system and its contribution to the development and progress of this theory of socialism with Chinese characteristics are mainly reflected in the following four aspects.

\subsection{Contribution and innovation to the theory of development economics}

In the past, China's development theory primarily focused on how to boost the savings rate and investment rate under the conditions of backward productivity and shortage economy, thereby accelerating the economic growth. Building a modern economic system, however, 
studies the ways to establish a high-quality economy in response to changes in major contradictions in the new era, under the conditions of "double surplus" of capital and commodities. The problem concerns no longer the shortage but the surplus, no longer the quantity but the quality, and no longer the absence of affluence but the characteristic of being fair or foul. Solving major structural imbalances in economic operations, such as imbalances within the real economy, between real economy and finance, or between real economy and real estate, is important. The policy tools and means used to correct structural imbalances under surplus economy conditions are also completely different from those used in the economic development under the shortage economy conditions; the latter mainly uses methods that promote rapid economic growth, and increase the savings and investment rates, whereas the former requires starting from two aspects: first, to improve the technical level and productivity of the real economy, and perform structural adjustment in pursuit of high quality, and second, to encourage financial innovation in the virtual economy and provide more high-quality financial assets for the growing needs of the society, to make up for the "asset shortage," stabilize asset bubbles and maintain a balanced relationship with the real economy. These are new issues for development policy and require new summaries and refinements for development theory.

\subsection{Contribution and innovation to industrial economics theory}

In the past, we have defined the construction of a modern industrial system, in the context of a developing large-scale economy, as comprehensively building a relatively stable modern agricultural foundation, a relatively developed manufacturing industry (especially the highlevel equipment manufacturing industry), and a full-fledged and rapidly developing modern service industry. This type of industry system construction aims to divide rather than integrate the links between industrial sectors. Thus, this system lacks the modern market economic awareness of inter-departmental resource flows and the balanced development where equal capital reaps equal benefits, and is prone to the formation of new structural segmentations in the original dualistic economy. The 19th CPC National Congress Report proposes the construction of a "Four-in-one" synergistic industrial system as the material basis of the modern economic system. Furthermore, the report creatively clarified the new goals of future industrial system construction and the synergetic development among various factors from the perspective of factor input rather than departmental division, as well as the general requirements for synergetic development of various factors. Thus, these insights are major innovations that take root in China's development practice, respect the laws governing the operation and development of the market economy, and contribute to the theory of modern industrial development.

\subsection{Contribution and innovation to modern economic growth theory}

Although the modern economic growth theory has always emphasized the decisive role of human, intellectual, and technological capital in growth, less research has focused on how to further apply the synergy of advanced production factors (such as S\&T innovation, modern finance and human resources), and even less on emphasizing how the input elements of the national economy serve the real economy. This situation is an important reason for the hollowing out of the industry and the bubble economy in Western countries. China's economic modernization process must attach great importance to this experience and lessons from the development of Western countries. When General Secretary Xi elaborated on the connotation and construction measures of the modern economic system, he repeatedly requested that the vigorous development of the real economy be a solid foundation for building a modern economic system. He pointed out that the real economy is the foundation of a country's economy, a fundamental source of wealth creation, and an important pillar of a country's prosperity. Important steps are necessary to deepen structural reforms on the supply side;

Building a modern economic system 
CPE 2,1

accelerate the development of advanced manufacturing industries; promote the deep integration of the internet, Big Data and artificial intelligence with the real economy; and promote the agglomeration of resource factors to the real economy. Economic policy and work forces should prioritize the real economy to create a down-to-earth and hardworking social environment for entrepreneurship development. This condition is an important theoretical guarantee for preventing the emergence of undesirable trends such as "underweighted real economy and overweighted virtual economy" in the track of modern economic growth.

\subsection{In the process of building a modern economic system}

China's practice may elicit rethinking on some theoretical propositions derived from Western economic practices in the past, and innovation on this basis to identify new problems and propose new experiences, rules, and conclusions that are closely related to national conditions. For example, the theory of socialist shared distribution with Chinese characteristics is a major innovation in the theory of capital-led distribution. On the basis of the decisive role of the market, the theory of the socialist market economic system that effectively exerts the role of the government is a major innovation of the Western market economic theory regarding the role of the market. The ecological economic theory characterized and directed by the concept of "green hills and clear waters are mountains of gold and silver" (i.e. a green environment furnishes endless wealth) is a major innovation in the theory of industrialization and modernization. The spatial economic theory that balances regional relations by climbing the global value chain and building a world-class advanced manufacturing industry, as well as the open economic development theory based on the "Belt and Road Initiative" and the construction of a global "Community of Common Destiny" are major innovations in the international economic theory that takes developing countries as subjects.

\section{References}

Liu, W. (2018), "Building a modern economic system with supply-side structural reform as the main line”, People's Daily, January 26, available at: http://opinion.people.com.cn/n1/2018/0126/c1003-2 9787763.html

Liu, Z. (2017), "A logical framework for deepening economic reform: promoting supply-side structural reform with government reform", Exploration and Free Views, Vol. 32 No. 6, pp. 99-104.

Liu, Z. (2018a), "Building a modern economic system: the general programme of economic construction in the new era", Journal of Shandong University (Philosophy and Social Sciences), Vol. 52 No. 1, pp. 1-6.

Liu, Z. (2018b), "The foundation of industrial system for high-quality development", People's Daily, March 20, available at: http://theory.people.com.cn/n1/2018/0320/c40531-29877263.html

Ning, J. (2017), "In-depth study and implementation of the policies of the 19th national congress of the Communist Party of China, accelerate the construction of a modern economic system", Macroeconomic Management, Vol. 32 No. 12, pp. 4-13.

Yang, W. (2017), "Three passes for high-quality economic development to overcome”, China Economic News Net, December 25, available at: www.cet.com.cn/ycpd/sdyd/1992237.shtml

\section{Corresponding author}

Zhibiao Liu can be contacted at: zbliu@nju.edu.cn

For instructions on how to order reprints of this article, please visit our website:

www.emeraldgrouppublishing.com/licensing/reprints.htm

Or contact us for further details: permissions@emeraldinsight.com 